\title{
KLASIFIKASI KELAYAKAN TELUR AYAM RAS (BROILER) MENGGUNAKAN METODE NAÏVE BAYES CLASSIFIER
}

\author{
Andri Maulana Iksan ${ }^{1}$, Rudi Hariyanto ${ }^{2}$, Anang Aris Widodo. ${ }^{3}$ \\ Fakultas Teknologi Informasi, Universitas Merdeka Pasuruan ${ }^{\mathbf{1 , 2 , 3}}$ \\ Andrelana702@gmail.com¹, Rudihariy4nt0@gmail.com², Anangariswidodo@gmail.com³
}

\begin{abstract}
Abstrak. Telur tetas merupakan telur fertil atau telur yang telah dibuahi baik secara alami maupun buatan, dihasilkan dari peternakan ayam pembibit bukan peternakan komersial Telur yang ditetaskan haruslah melalui proses seleksi, tidak semua telur tetas dapat digunakan dalam penetasan. Faktor utama yang perlu diperhatikan dalam memilih telur tetas adalah kualitas telur, jika kualitas telur yang akan ditetaskan buruk maka presentase jumlah telur yang menetas rendah. Bobot telur tetas haruslah seragam sehingga besarnya juga seragam, yaitu tidak terlalu besar dan tidak terlalu kecil. Telur yang terlalu besar menyebabkan kantung udara terlalu kecil untuk perkembangan embrio sehingga telur akan terlambat untuk menetas. Ada beberapa kendala yang dihadapi karyawan untuk menyeleksi telur tetas diantaranya kurang teliti, faktor usia yang yang sudah tidak produktif dan juga faktor kelelahan mengakibatkan kurang fokus dalam menyeleksi. Pada permasalahan ini maka penelitian ini adalah bagaimana menentukan kelayakan telur dan dan klasifikasi dari citra telur layak dan tidak. Proses klasifikasi kelayakan telur ini dilakukan menggunakan Nä̈ve Bayes Classifier. Data yang dikumpulkan berjumlah 100 data citra telur terbagi menjadi 80 data latih dan 20 data uji. Dari hasil pengujian didapatkan hasil akurasi sebesar $75 \%$ dengan 20 data uji.
\end{abstract}

Kata Kunci: Telur,Klasifikasi, Nä̈ve Bayes Classifier

\section{PENDAHULUAN}

Bagian Telur tetas merupakan telur fertil atau telah dibuahi, dihasilkan oleh peternakan ayam pembibit, bukan dari peternakan ayam komersial yang digunakan untuk penetasan. Telur tetas yang digunakan dalam proses penetasan adalah telur yang telah diseleksi. Syarat telur tetas yang baik yaitu sehat dan produktivitasnya tinggi, umur telur dan kualitas fisik telur (bentuk, berat, keadaan kerabang) (Suprijatna, 2005). Kualitas telur tetas tergantung dari kualitas induk, kualitas pakan yang dikonsumsi, kondisi kesehatan ayam, week production, dan suhu (Kholis dan Sitanggang, 2001).

Tahap awal dari proses penetasan dimulai dari penyeleksian telur (grading). Grading adalah proses seleksi telur menjadi dua bagian yaitu telur yang layak ditetaskan atau disebut Heaching Egg (HE) dan telur yang yang tidak layak ditetaskan (Grade Out). Adapun ciri/kriteria telur yang layak tetas dan tidak layak tetas, untuk telur yang layak tetas ciri-cirinya bentuk telur normal yaitu berbentuk oval, warna kulit telur berwarna coklat gelap, kerabang telur tidak tipis berukuran $0,3 \mathrm{~mm}$ dan kulit telur tidak kasar dan bintik-bintik. Untuk telur yang tidak layak tetas ciri-cirinya telur kotor (dirty), cacat (benjol,lonjong), besar (jumbo), kerabang tipis, warna tidak seragam, kerabang bintik-bintik kasar dan telur retak. Dalam proses grading ini terdapat beberapa kendala dalam menentukan telur yang layak dan tidak layak ditetaskan. Diantaranya, pada saat proses grading masih banyak telur yang seharusnya tidak layak tetas (Grade Out) masih banyak yang masuk kedalam telur yang layak tetas (HE). Ini dikarenakan 
masih kurang telitinya Quality Control (QC) dalam menyeleksi telur dan kurang teliti dalam mengenali kriteria telur yang layak dan tidak layak. Penelitian ini untuk menerapkan metode Nä̈ve Bayes Classifier guna mencari klasifikasi data uji, membedakan telur ayam yang layak tetas dengan telur ayam yang tidak layak tetas, seperti yang dilakukan oleh : Susilo (2019) Klasifikasi Kualitas Ikan Tongkol Beku Menggunakan Metode Nä̈ve Bayes memiliki akurasi sebesar 72.727\%. Penelitian selanjutnya dilakukan oleh Abd. Ghofur (2016) Klasifikasi Naive Bayes Untuk Memprediksi Kualitas Cabai Mendapatkan hasil tingkat akurasi prediksi yang sesuai dengan pendapat pakar mencapai 93.33\%. Selanjutnya dilakukan oleh Ciputra (2018) Klasifikasi Tingkat Kematangan Buah Apel Manalagi Dengan Algoritma Naive Bayes mendapatkan hasil akurasi mencapai 63\%. Dan selanjutnya penelitian dilakukan oleh Liantoni (2015) Klasifikasi Daun Herbal Menggunakan Metrode Nä̈ve Bayes Classifier Dan $K$ - Nearest Neighbor hasil uji coba dengan Metrode Nä̈ve Bayes Classifier mendapat hasil nilai akurasi $75 \%$, sedangkan dengan metode K-Nearest Neighbor mendapat nilai akurasi 70,83\%. Hal ini menunjukkan bahwa kinerja NBC lebih baik dibandingkan dengan metode K-NN. Penelitian selanjutnya oleh Hafsah (2015) Deteksi Otomatis Penyakit Kulit Menggunakan Algoritma Metode Nä̈ve Bayes memiliki nilai akurasi sebesar 73,33\%.

\section{METODE PENELITIAN}

Bagian $\mathrm{Bab}$ ini menjelaskan tentang metodologi penelitian yang digunakan pada penelitian ini, yang terdiri dari (1) Studi Literatur, (2) Perancangan Sistem, (3) Algoritma Nä̈ve Bayes Classifier, (4) Pengujian, (5) Evaluasi Hasil Pengujian.

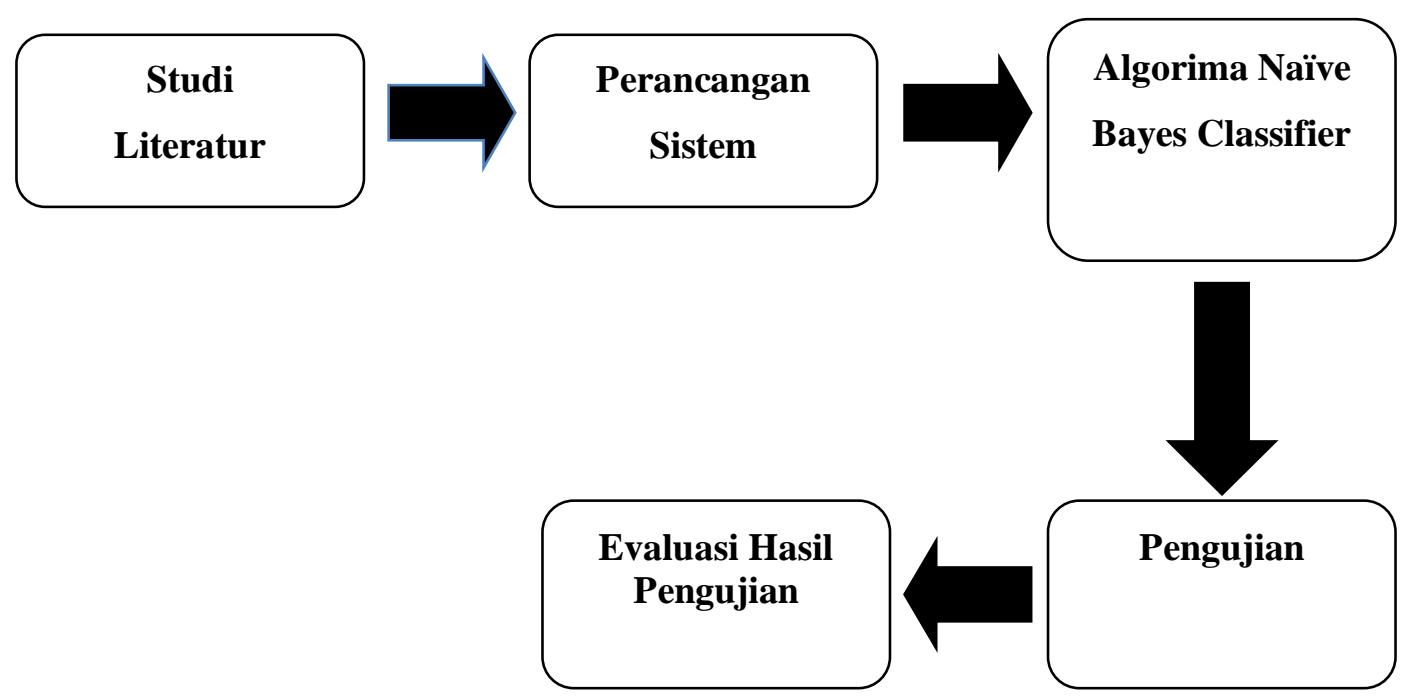

Gambar 1. Diagram Alir Pengujian Penelitian

- Studi Literatur

Untuk melakukan penelitian ini melakukan studi literatur berdasarkan topik penelitian yang diambil. Studi literatur yang dikaji berkaitan dengan Klasifikasi Kelayakan Telur Ayam Ras (Broiler) menggunakan metode Naive bayes classifier

Dari pemaparan literatur di atas dapat menjadi dasar dalam penelitian ini dengan menganalisa serta menentukan perbedaan telur layak tetas dan tidak layak tetas, dengan tujuan mendapatkan hasil dan nilai probabilistik yang akurat.

- Perancangan Sistem

a. Tempat Penelitian 
Dalam penelitian ini tempat yang telah dilakukan selama 1 minggu di perusahaan peternakan CJ INDONESIA FARM NGEMBAL tepatnya di PT. Super Unggas Jaya Kecamatan Tutur, Desa Ngembal, Kabupaten Pasuruan.

b. Alur Sistem

Alur perencangan sistem yang berada dalam penelitian ini dengan beberapa langkah ang harus di lakukan sebagai berikut:

Data Training

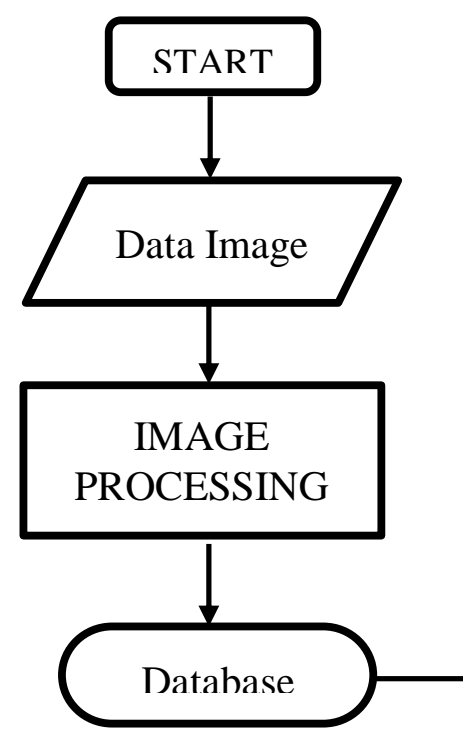

Data Testing

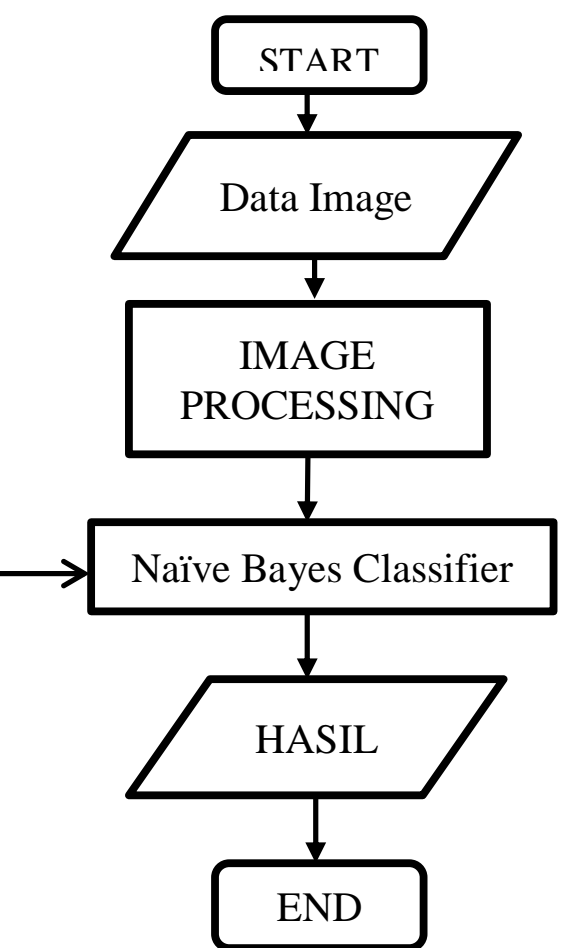

Gambar 2. Flowchart Alur Sistem

c. Desain Antarmuka

Perencanaan sistem merupakan desain antarmuka untuk menampilkan citra yang akan diproses dalam system yang akan dibuat. Desain antarmuka tersebut dapat dilihat dalam gambar 3.

Proses pengujian berfungsi untuk mengidentifikasi objek, berikut fungsi-fungsI yang ada dalam proses pengujian :

1. Buka gambar : untuk memilih gambar mana yang akan diidentifikasi.

2. Training Data : untuk melakukan proses training data gambar.

3. Ekstraksi fitur : untuk melakukan ekstraksi fitur pada citra dan melakukan klasifikasi dan hasil ekstraksi. 


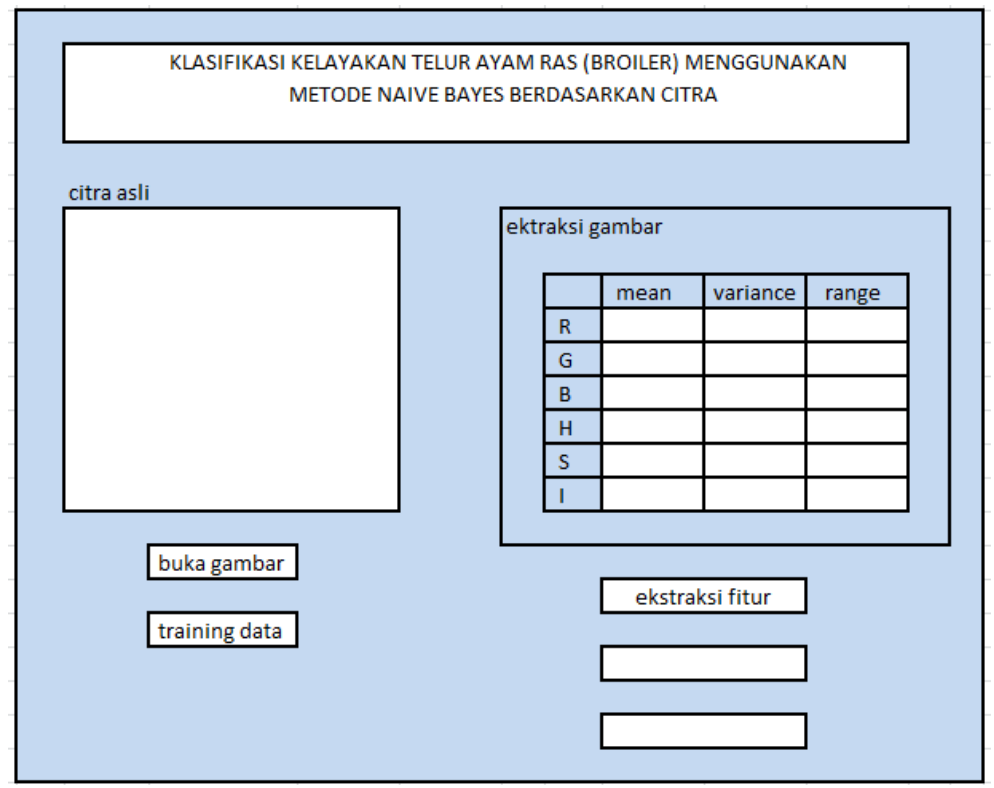

Gambar 3. Desain Antarmuka Proses Pengujian

\section{- Nä̈ve Bayes Classifier}

Naïve Bayes merupakan sebuah metode penggolongan berdasarkan probabilitas sederhana dan dirancang untuk dipergunakan dengan asumsi bahwa antar satu kelas dengan kelas yang lain tidak saling tergantung (independen). Pada klasifikasi Nä̈ve Bayes, proses pembelajaran lebih ditekankan pada mengestimasi probabilitas. Keuntungan dari pendekatan ini yaitu pengklasifikasian akan mendapatkan nilai error yang lebih kecil ketika data set berjumlah besar. Selain itu klasifikasi Nä̈ve Bayes terbukti memiliki akurasi dan kecepatan yang tinggi saat diaplikasikan ke dalam basis data dengan jumlah yang besar. Formulasi Nä̈ve Bayes untuk klasifikasi menurut Prasetyo (2012) adalah sebagai berikut:

$$
P(Y \mid X)=\frac{P(Y) \prod_{i=1}^{q} P\left(X_{i} \mid Y\right)}{P(X)}
$$

$$
\begin{array}{ll}
\begin{array}{l}
\text { Dimana: } \\
\mathrm{P}(\mathrm{Y} \mid \mathrm{X})
\end{array} & =\text { probabilitas data dengan vektor } \mathrm{X} \text { pada kelas } \mathrm{Y} . \\
\mathrm{P}(\mathrm{Y}) & =\text { probabilitas awal kelas } \mathrm{Y} \text { (prior probability). } \\
\prod_{i=1}^{q} P\left(X_{i} \mid Y\right) & =\text { probabilitas independen kelas } \mathrm{Y} \text { dari semua fitur } \\
& \text { alam vektor } \mathrm{X} . \\
\text { Nilai } \mathrm{P}(\mathrm{X}) & =\text { probabilitas dari } \mathrm{X} .
\end{array}
$$

Data yang digunakan dalam penelitian ini adalah data yang bernilai numerik memiliki promentahlitas normal atau Gaussian dengan menghitung nilai dari rerata $\mu$ dan standar deviasi $\sigma$ pada setiap class, yang dirumuskan pada persamaan (1) dan (2).

Rumus Mean

$$
\mu=\frac{1}{n} \sum_{i=1}^{n} x i \quad \text { dan }
$$


Keterangan :

$$
\begin{array}{ll}
\mu & =\text { Nilai rata }- \text { rata hitung (mean) } \\
\mathrm{xi} & =\text { Nilai data } \mathrm{ke}-\mathrm{i} \\
\mathrm{n} & =\text { Banyaknya data }
\end{array}
$$

Rumus Standard Deviasi

$$
\sigma=\sqrt{\frac{\sum_{i=1}^{n}(x 1-\mu)^{2}}{n-1}}
$$

Keterangan :

$$
\begin{array}{ll}
\mathrm{Xi} & =\text { Data } \mathrm{ke}-\mathrm{i} \\
\mu & =\text { Nilai rata }- \text { rata hitung (mean) } \\
\mathrm{n} & =\text { Banyaknya data }
\end{array}
$$

Dimana pencarian promentahlitas $\mathrm{X}$ berdasarkan kondisi pada hipotesis $C i$ pada persamaan (3) dan (4).

$$
\begin{aligned}
& P(x)=\frac{1}{\sqrt{2 \pi \sigma^{2}}} e^{-\frac{(x-\mu)^{2}}{\sigma^{2}}} \\
& P(X k \mid C i)=g(x i, \mu i, \sigma i)
\end{aligned}
$$

Keterangan :

$$
\begin{aligned}
\mathrm{P} & : \text { Peluang } \\
x & : \text { Kelas yang dicari } \\
\mu & : \text { Mean, menyatakan rata-rata dari seluruh atribut } \\
\sigma & : \text { Standar deviasi, menyatakan varian dari seluruh atribut }
\end{aligned}
$$

\section{HASIL DAN PEMBAHASAN}

Dari hasil penelitian dan perancangan aplikasi yang suadah dilakukan mulai dari tahap penelitian dan perancangan aplikasi Klasifikasi Telur Ayam Ras (Broiler) Berbasis Matlab,menggunakan sebuah perangkat computer. Dengan dilakukan implementasi terhadap aplikasi ini dengan cara pengujian aplikasi yang akan dibuat. Berikut contoh hasil aplikasi yang sudah dirancang :

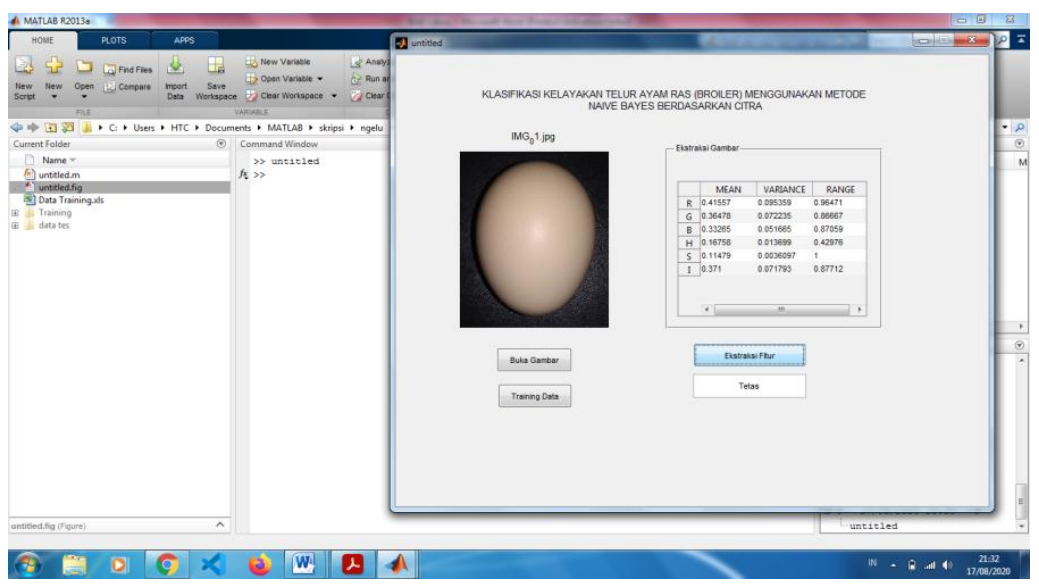


Gambar 4. Aplikasi Klasifikasi Telur Ayam Ras (Broiler) Berbasis Matlab

Berikut merupakan hasil uji coba program, dari data image yang digunakan sebanyak 20 pengujian citar telur uji.

Tabel 1. Hasil Uji Coba

\begin{tabular}{ccccc}
\hline No & Citra & Kelas Asli & Kelas Prediksi & Benar/Salah \\
\hline 1. & Image_01.jpg & Layak & Tidak Layak & Salah \\
\hline 2. & Image_02.jpg & Tidak Layak & Tidak Layak & Benar \\
\hline 3. & Image_03.jpg & Layak & Tidak Layak & Salah \\
\hline 4. & Image_04.jpg & Layak & Tidak Layak & Salah \\
\hline 5. & Image_05.jpg & Tidak Layak & Tidak Layak & Benar \\
\hline 6. & Image_06.jpg & Layak & Layak & Benar \\
\hline 7. & Image_07.jpg & Layak & Tidak Layak & Salah \\
\hline 8. & Image_08.jpg & Layak & Tidak Layak & Salah \\
\hline 9. & Image_09.jpg & Layak & Layak & Benar \\
\hline 10. & Image_10.jpg & Layak & Layak & Benar \\
\hline 11. & Image_11.jpg & Layak & Layak & Benar \\
\hline 12. & Image_12.jpg & Layak & Layak & Benar \\
\hline 13. & Image_13.jpg & Layak & Layak & Benar \\
\hline 14. & Image_14.jpg & Layak & Layak & Benar \\
\hline 15. & Image_15.jpg & Layak & Layak & Benar \\
\hline 16. & Image_16.jpg & Tidak Layak & Tidak Layak & Benar \\
\hline 17. & Image_17.jpg & Tidak Layak & Tidak Layak & Benar \\
\hline 18. & Image_18.jpg & Tidak Layak & Tidak Layak & Benar \\
\hline 19. & Image_19.jpg & Tidak Layak & Tidak Layak & Benar \\
\hline 20. & Image_20.jpg & Tidak Layak & Tidak Layak & Benar \\
\hline
\end{tabular}

Berdasarkan hasil uji coba dari tabel .1 terlihat bahwa Naïve Bayes Classifier memiliki nilai akurasi sebesar $75 \%$ dan 15 citra telur yang bernilai benar atau sesuai dengan kelas asli, dan 5 citra telur lainnya bernilai salah atau tidak sesuai dengan kelas asli.

$$
\begin{aligned}
\text { akurasi } & =\frac{\text { jumlah data benar }}{\text { jumlah keseluruhan data }} \times 100 \% . \\
& =\frac{15}{20} \times 100 \% \\
& =75 \%
\end{aligned}
$$

\section{PENUTUP}

- Kesimpulan: 1). Aplikasi ini dapat memudahkan pekerjaan karyawan dalam membedakan kriteria telur layak tetas dan tidak layak tetas. Kedepannya juga bisa dijadikan acuan standart kelayakan telur untuk perusahaan peternakan. 2). Metode naïve bayes classifier cukup tepat digunakan karena hasil akurasi yang didapat dari 20 data uji citra telur hasil algoritma naïve bayes classifier menghasilkan nilai akurasi yang cukup sempurna dengan nilai $75 \%$.

- Saran 1). Untuk pengembangan penelitian lebih lanjut mungkin dapat diterapkan dengan menggunakan metode lain selain naïve bayes classifier agar mendapat tingkat akurasi lebih baik lagi. 2).Pada penelitian lebih lanjut mungkin dapat diterapkan dengan berbasis android. 


\section{DAFTAR PUSTAKA}

Arhami, Muhammad dan Anita Desiani. (2005). Pemrograman MATLAB. Yogyakarta. ANDI.

Asmara, R. A., Andjani, B. S., Rosiani, U. D., \& Choirina, P. (2018). Klasifikasi Jenis Kelamin Pada Citra Wajah Menggunakan Metode Naive Bayes. Jurnal Informatika Polinema, 4(3), 212. https://doi.org/10.33795/jip.v4i3.209

Ahsan. M, Klasifikasi Proses Business Data Mahasiswa Universitas Kanjuruhan Malang Menggunakan Teknik Data Mining. Prosiding Seminar Nasional Hasil Penelitian, 2.2016.http://semnas.unikama.ac.id/lppm/prosiding/2016/PENELITIAN/SAINS\%20D AN\%20TEKNOLOGI/Moh.\%20Ahsan\%20UNIKAMA.pdf

Ciputra, A., Setiadi, D. R. I. M., Rachmawanto, E. H., \& Susanto, A. (2018). Klasifikasi Tingkat Kematangan Buah Apel Manalagi Dengan Algoritma Naive Bayes Dan Ekstraksi Fitur Citra Digital. Simetris: Jurnal Teknik Mesin, Elektro Dan Ilmu Komputer, 9(1), 465-472. https://doi.org/10.24176/simet.v9i1.2000

Gunadi, I.A. \& Sukajaya, I.N. (2017). An Improvement of Mouth Detection Implementing Color Features Extraction Method for Facial Images with Lighting Problems. IEEE International Conference on Advanced Informatics, Concepts, Theory, and Applications (ICAICTA) : 1-5.

Ghofur, A. (2016). Implementasi Metode Klasifikasi Naive Bayes Untuk Memprediksi Kualitas Cabai. Jurnal Ilmiah Informatika, 1(1), 32-38. https://doi.org/10.35316/jimi.v1i1.441

Indriyono, B. V., Utami, E., \& Sunyoto, A. (2015). Klasifikasi Jenis Buku Berdasarkan Judul dan Sinopsis Menggunakan Metode Naive Bayes Classifier (Studi Kasus: STMIK Kadiri). Sisfo, 05(04). https://doi.org/10.24089/j.sisfo.2015.09.010

Izzati Saila Hafsah, P. A. (2015). Deteksi Otomatis Penyakit Kulit Menggunakan Algoritma Naive Bayes. 5, 1-6.

Kavitha, J.C. \& Suruliandi, A. (2016). Texture and Color Feature Extraction for Classification of Melanoma using SVM. IEEE International Conference on Computing Technologies and Intelligent Data Engineering (ICCTIDE'16) :1-6.

Kholis, S. dan M. Sitanggang. 2001. Ayam Arab dan Poncin Petelur Unggul AgroMedia, Jakarta.

Lasfeto, Dedy Barnabas dan Oky Dwi Nurhayati. (2008). Analisis Statistika Menggunakan MATLAB.Yogyakarta.GRAHA ILMU.

Liantoni, F., \& Nugroho, H. (2015). Klasifikasi Daun Herbal Menggunakan Metode Naïve Bayes Classifier Dan Knearest Neighbor. Jurnal Simantec, 5(1), 9-16.

Lionnie, R. \& Alaydrus, M. (2017). A Comparison of Human Skin Color Detection for Biometric Identification. IEEE International Conference on Broadband Communication, Wireless Sensors and Powering (BCWSP) : 1-5. 
Mulyani, E.D.S., Susanto, \& Poniman, J. 2017. Classification of Maturity Level of Fuji Apple Fruit with Fuzzy Logic Method. IEEE 5th International Conference on Cyber and IT Service Management (CITSM) : 1-4.

Prasetyo, E., (2012). Data Mining Konsep dan Aplikasi Menggunakan Matlab, Andi Offset, Yogyakarta

Rasyaf, M. 1990. Bahan Makanan Unggas di Indonesia. Kanisius, Yogyakarta.

Rasyaf, M. 1995. Pengelolaan Usaha Peternakan Ayam Pedaging. Gramedia Pustaka Utama. Bogor.

Sahid. (2005). Pengantar Komputasi Numerik dengan MATLAB. Yogyakarta. C.V. ANDI OFFSET.

Setyaputra, A. A., Sutojo, T., Informatika, T., Komputer, I., Dian, U., Semarang, N., \& No, J. N. I. (2012). Klasifikasi Daging Ayam Menggunakan Naive Bayes Classifier Berdasarkan Pada Ekstraksi Fitur Tekstur Histogram Chicken Meat Classification Using Naive Bayes Classifier Based On Histogram-based Feature Texture Extraction. x.

Sudaryani, T. dan Santoso. 2003. Pembibitan Ayam Ras. Penebar Swadaya, Jakarta.

Sugiyono, 2013, Metodelogi Penelitian Kuantitatif, Kualitatif Dan R\&D. (Bandung: ALFABETA).

Suprijatna, E. U, Atmomarsono. R, Kartasudjana. 2005. Ilmu Dasar Ternak Unggas. Penebar Swadaya, Jakarta.

Tri Yuwanta, 1983. Bebarapa Metode Praktis Penetasan Telur. Dirjen DIKTI Depdikbud. Jakarta.

Yulianto, D., Whidhiasih, R. N., \& Maimunah, M. (2018). Klasifikasi Tahap Kematangan Pisang Ambon Berdasarkan Warna Menggunakan Naive Bayes. PIKSEL: Penelitian Ilmu Komputer Sistem Embedded and Logic, 5(2), 60-67. https://doi.org/10.33558/piksel.v5i2.268 